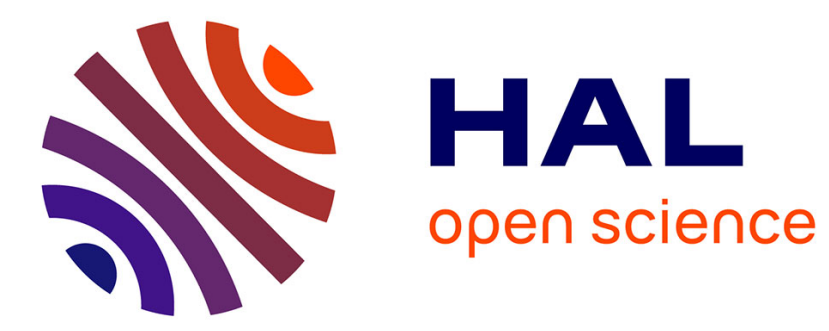

\title{
Salt precipitation and trapped liquid cavitation in micrometric capillary tubes.
}

Majda Bouzid, Lionel Mercury, Arnault Lassin, Jean-Michel Matray

\section{To cite this version:}

Majda Bouzid, Lionel Mercury, Arnault Lassin, Jean-Michel Matray. Salt precipitation and trapped liquid cavitation in micrometric capillary tubes.. Journal of Colloid and Interface Science, 2011, 360 (2), pp.768-776. 10.1016/j.jcis.2011.04.095 . insu-00589810

\section{HAL Id: insu-00589810 https://hal-insu.archives-ouvertes.fr/insu-00589810}

Submitted on 2 May 2011

HAL is a multi-disciplinary open access archive for the deposit and dissemination of scientific research documents, whether they are published or not. The documents may come from teaching and research institutions in France or abroad, or from public or private research centers.
L'archive ouverte pluridisciplinaire HAL, est destinée au dépôt et à la diffusion de documents scientifiques de niveau recherche, publiés ou non, émanant des établissements d'enseignement et de recherche français ou étrangers, des laboratoires publics ou privés. 


\section{SALT PRECIPITATION AND TRAPPED LIQUID CAVITATION IN MICROMETRIC \\ CAPILLARY TUBES}

Majda BouZID ${ }^{1,2}$, Lionel MERCURY ${ }^{3, *}$, Arnault LASSIN $^{4}$, Jean-Michel MATRAY ${ }^{2}$

${ }^{1}$ IDES, UMR 8148 CNRS/Université Paris-Sud, bâtiment 504, 91405 Orsay Cedex, France

${ }^{2}$ IRSN, DEI/SARG/LR2S, BP 17, 92262 Fontenay-aux-Roses Cedex, France

${ }^{3}$ Institut des Sciences de la Terre d'Orléans, UMR 6113 CNRS-INSU/Universités d'Orléans et de Tours, $1 \mathrm{~A}$ rue de la Férolerie, 45071 Orléans Cedex, France.

${ }^{4}$ BRGM, Water Division, 3 av. C. Guillemin, 45060 Orléans Cedex 2, France

“Corresponding author: lionel.mercury@univ-orleans.fr

Keywords: porous network, unsaturated zone, capillary geochemistry

Running head: Stable and metastable aqueous solutions in capillaries 


\section{Abstract.}

Laboratory evidence shows that the occurrence of solid salt in soil pores causes drastic changes in the topology of the porous spaces and possibly also in the properties of the occluded liquid. Observations were made on $\mathrm{NaCl}$ precipitation in micrometric cylindrical capillary tubes, filled with a $5.5 \mathrm{M} \mathrm{NaCl}$ aqueous solution and submitted to drying conditions. Solid plug-shaped $\mathrm{NaCl}$ (halite) commonly grows at the two liquid-air interfaces, isolating the inner liquid column. The initially homogeneous porosity of the capillary tube becomes heterogeneous because of these two $\mathrm{NaCl}$ plugs, apparently closing the micro-system on itself. After three months, we observed cavitation of a vapor bubble in the liquid behind the $\mathrm{NaCl}$ plugs. This event demonstrates that the occluded liquid underwent a metastable superheated state, controlled by the capillary state of thin capillary films persisting around the $\mathrm{NaCl}$ precipitates. These observations show, first, that salt precipitation can create a heterogeneous porous medium in an initially regular network, thus changing the transfer properties due to isolating significant micro-volumes of liquid. Second, our experiment illustrates that the secondary salt growth drastically modifies the thermo-chemical properties of the occluded liquid and thus its reactive behavior. 


\section{INTRODUCTION}

Large multiphase systems in nature, such as the unsaturated zone of soils (UZ hereafter), or depleted deep aquifers, offer interesting physical geochemistry problems, directly connected to reactive mass-transport processes. As such, they are of potential importance in many environmental issues, including $\mathrm{CO}_{2}$ storage, aquifer recharge management, or combating soil salinization. UZ hydrodynamics focus on many efforts and present interesting aspects, but UZ geochemistry attracts less attention since it is usually thought to be quite similar to water-saturated geochemistry. Actually, though, the chemical reactivity of solids and gases changes when coming in contact with a capillarized liquid (e.g. [1-11]). However, a remaining key question is whether it is possible that aqueous solutions in real media acquire a capillary signature that can affect the reactive transport balance in natural systems.

The peculiarities of the solid-liquid-air equilibrium, i.e. its "multiphase" feature, introduce capillary physics (and chemistry) into the already complicated framework of liquid flow in pores. This forces us to consider the heterogeneity of a porous network, since the liquid-air distribution depends primarily on the pore size (Young-Laplace law) at the precise location of the interface. Furthermore, such filled channels can be distinguished into flowing and notflowing (mobile and immobile) ones, since the capillary pressure can counteract gravity or any head gradient. Depending on the local situation, the hydraulic conductivity inside a variably-saturated porous medium is close to the saturated value or much smaller. Finally, the capillary water can be perfectly stable water if it obeys the Young-Laplace equilibrium, or, if not, will be superheated metastable water prone to nucleating vapor at any time (e.g. [1219]).

A superheating-apt situation readily occurs in natural materials where the pore network has a so-called "ink-bottle" configuration (e.g. [20-21]). This ensures a mechanical (Young-Laplace law) capillary equilibrium at the (narrow) liquid-air interfaces, but not necessarily inside the capillary volume located in larger pores than those supporting the water-air interfaces. As the 
chemical potential is everywhere the same (Kelvin law), the inner part of the capillary water is no longer thermodynamically stable, but superheated. The ink-bottle effect is generally discussed in relation to volume/pressure curves of soil-water and their hysteretic characteristics. But it also is linked to drainage mechanisms in wet porous media through cavitation of the superheated pore water (e.g. $[15-16,19])$. On the hydrodynamic side this explains liquid displacement according to a non-piston-flow process; on the geochemical side, however, this implies interaction between the solid matrix and a superheated solution as long as no cavitation occurs. Moreover, superheated water is known to be an efficient "green" solvent (e.g. [22-23]), an empirical finding confirmed (with nuances) by studying its thermodynamic properties [1,2,4,7-10].

Though the ink-bottle effect is a well-known concept, it is often overlooked in reactive transport modeling at the UZ scale. The present paper aims at demonstrating, through very simple experiments, that this effect can occur in any material or field setting submitted to drying conditions, even if the geometry of the host pore network is a priori unable to display it. The operational objective was to provide new evidence that modification of a channel intube configuration (through phase transition) has an impact on the thermodynamic state and thus on the chemical reactivity of the occluded water with respect to its environment. To this end, open, micrometric, constant-sized and cylindrical capillary tubes were filled with saline solutions and submitted to evaporating conditions, to enable salt precipitation and a change in pore topology. The phase transitions inside the tubes were observed during one year.

\section{PROTOCOL AND EXPERIMENTAL TECHNIQUES}

\subsection{Capillaries and salt solutions}

Capillary tubes were purchased from Polymicro Technologies LLC, which proposes polyimide-coated fused silica materials, with internal diameters from 5 to $180 \mu \mathrm{m}$. We tested a wide range of diameters, using successively $5,10,20,75,100$ and $180 \mu \mathrm{m}$ tubes. A reference experiment was carried out in a Petri dish, to see how salt growth happens under 
the same environmental conditions (temperature, relative humidity, initial chemical composition), but without any geometrical restriction.

The aqueous solutions were hand-made (NormaPur $\mathrm{NaCl}$ powder, Prolabo; milli-Q water) close to saturation: $\mathrm{NaCl}$ concentration was $5.5 \mathrm{~mol} / \mathrm{kg}$, slightly undersaturated with respect to halite (saturation is at $6.2 \mathrm{~mol} / \mathrm{kg}$ at $25^{\circ} \mathrm{C}$ and $10^{5} \mathrm{~Pa}$ ).

\subsection{Experimental procedure and in situ observations}

Each tube (about $10 \mathrm{~cm}$ long) was completely filled by capillarity with the brine before being put in a dry chamber with controlled relative humidity $(\mathrm{RH}=24 \%)$ and temperature $\left(20^{\circ} \mathrm{C}\right)$. The $\mathrm{RH}$ was kept constant by a $\mathrm{LiCl}$ solution put at the bottom of the dry chamber, and was recorded with a humidity/temperature data logger (EL-USB-2, LASCAR-Easylog). The dry chamber also contained a Petri dish with the same initial solution as that filling the tubes.

We tested the influence of a saturated atmosphere by putting certain tubes in a dry chamber whose $\mathrm{RH}$ was controlled by a saturated $\mathrm{NaCl}$ solution $(\mathrm{RH}=75 \%)$. After a small retreat of the meniscus inside the tubes, nothing more occurred and the capillary columns remained unchanged; obviously, a dry (with respect to the sampled solution) external atmosphere was required to sustain the in-tube evaporation. Otherwise, external demand was the only driving force of the subsequent events (salt precipitation, capillarization, cavitation, see below).

The capillary tubes were regularly removed from the dry chamber and observed with an optical microscope (Leica DM4000B, equipped with a DALSA camera). Different characteristic distances were measured, such as the length between each inlet of the tube and the related liquid-air interface, the distance separating the two liquid-air interfaces, the location of any precipitate inside the tube. This provided a good idea on the dynamics of meniscus retreat and thus on the symmetry of the phenomena. Unfortunately, the optical field of our microscope did not cover the total length of the capillary column inside the tubes, so that the longest distances, especially those between the two liquid-air interfaces (i.e. the length of the water column), as measured were not really accurate and did not permit a quantitative comparison among the tubes. 


\section{RESULTS AND INTERPRETATION}

\subsection{Evaporating the solution}

The first stage of the experiment was a regular evaporation of water inside the tubes due to the conditions in the dry chamber atmosphere $(\mathrm{RH}=24 \%)$. To quantify this part of the process, we measured the variation in length between the liquid-air meniscus and the tube inlet over time. This provides the rate of drying, or the derivative of mass content over time. In a uniform, rigid, constant-sized capillary tube, filled with a volatile liquid, and maintained in contact with an "infinite" dry atmosphere, this drying rate should be constant. Vapor is transferred by gas diffusion from the inner liquid-air interface where liquid vaporizes to the external dry atmosphere. This is a slow evaporation process, for which the thermal change related to phase transition is negligible, and so water loss over time should obey the Stefan law (e.g. [24]):

$$
z-z^{\circ}=\sqrt{\frac{2 M_{v} P_{a} D}{\rho_{l} R T} \ln \left(\frac{1}{1-x_{e}}\right)\left(t-t^{\circ}\right)}
$$

where $z^{\circ}$ is the position of the liquid-air meniscus $(0 \mathrm{~m})$ at initial time $t^{\circ}(0 \mathrm{~s}) ; z$ (in meters) is its location at a given time $t$ (in seconds); $M_{v}$ is the molar mass of the volatile species (here, water: $0.018 \mathrm{~kg} / \mathrm{mol}) ; P_{a}$ is the atmospheric pressure $\left(10^{5} \mathrm{~Pa}\right) ; \rho_{l}$ is the volumetric mass of the brine $\left(1150 \mathrm{~kg} / \mathrm{m}^{3}\right) ; \mathrm{R}$ is the gas constant $(8.31 \mathrm{~J} / \mathrm{mol} . \mathrm{K}) ; \mathrm{T}$ is the Kelvin temperature $(293 \mathrm{~K}) ; x_{e}$ is the molar fraction of vapor at the liquid-air interface, taken as the molar fraction of the water vapor in air (here $x_{e}=0.0173$, calculated after the $2338 \mathrm{~Pa}$ saturation partial pressure of water vapor at $20{ }^{\circ} \mathrm{C}(293 \mathrm{~K})$ and $75 \% \mathrm{RH}$ which is the characteristic $\mathrm{RH}$ value of the $\mathrm{NaCl}$ brine saturated with respect to halite); and $\mathrm{D}$ is the diffusion coefficient of vapor in the air from the interface toward the dry atmosphere (in $\mathrm{m}^{2} / \mathrm{s}$ ).

According to this expression, the associated graph should be a linear plot of the retreat length of the meniscus $\left(z-z^{9}\right)$ as a function of the square root of time $t$ (Fig. 1). The experimental points measured (before $\mathrm{NaCl}$ plugging) actually meet this linearity condition. 


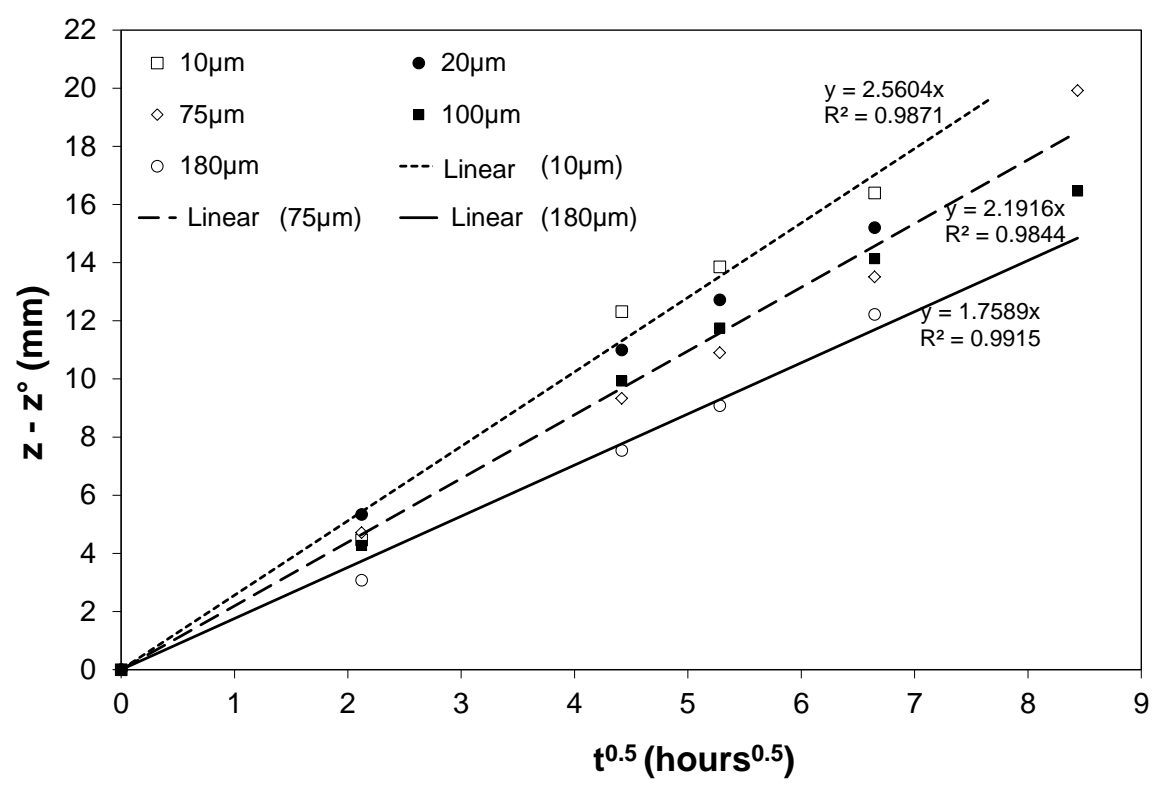

Figure 1. Meniscus retreat of the liquid-air meniscus $\left(z-z^{\circ}\right)$ as a function of time. The linear relationship observed for all experiments irrespective of tube radius meets the Stefan law, meaning that the drying dynamics follow a diffusive behavior.

Therefore, the evaporation rate was essentially constant and controlled by external demand, and the dynamics of our experiments were dominated by diffusion in the gas phase. The data show a slight dependency on channel size (increasing slope with decreasing diameter), which was not expected from equation 1 , indicating that the mechanistic process is probably more complex in detail. However, we can simplify by estimating that the slope is almost constant across the different tube diameters, in order to calculate the resulting diffusion coefficient with equation $1: \mathrm{D} \approx 6.2( \pm 1 \cdot 4) \cdot 10^{-5} \mathrm{~m}^{2} / \mathrm{s}$. This calculated value compares favorably with the usual diffusion-coefficient value of water vapor in air $\left(D_{\mathrm{H} 2 \mathrm{O}-\text { air }}=2.42 .10^{-5} \mathrm{~m}^{2} / \mathrm{s}\right.$ at $20^{\circ} \mathrm{C}$ [25]).

The dynamics associated to our vaporization experiment show a reasonable consistency between the results and the Stefan law, despite showing underlying complexities. This consistency allows us to assume that the vapor-pressure profile linearly increases from the $24 \% \mathrm{RH}$ of air at the outlet of the tube to an almost saturated value $\left(\mathrm{RH}_{\text {SATURATED }}=75 \%\right)$ at the brine-air interface (diffusive profile). 


\subsection{The first phase transition: $\mathrm{NaCl}$ precipitation}

Figure 1 plots the drying stage, before the aqueous solution reaches saturation with respect to $\mathrm{NaCl}$, leading to salt precipitation and the subsequent occlusion of the tube. This stage lasted between 40 and 60 hours (Figs. 1-2) and led to isolating a liquid column between two $\mathrm{NaCl}$-made plugs located at the liquid-air interfaces inside the tube.

As demonstrated by direct observations, the supersaturation required to cause precipitation was fed by continuous evaporation of the in-tube aqueous solution, driven by the external dry atmosphere. Following the meniscus retreat distance with time, we calculated the water loss over time and then the chemical enrichment in the residual solution (Fig. 2). We also evaluated the size of the precipitate and thus the mass of precipitated solid. This allowed calculating the ionic activity product $(Q)$ of the reaction: $\mathrm{NaCl}=\mathrm{Na}^{+}+\mathrm{Cl}^{-}$, using the Pitzer model for calculating activity coefficients. Q was then compared to the corresponding equilibrium constant $(K)$, giving the so-called saturation index (noted $S I): S I=\log Q / K$. A nil value characterizes the solid-solution equilibrium, while positive values sign a supersaturated solution with respect to solid, and negative values an undersaturated solution.

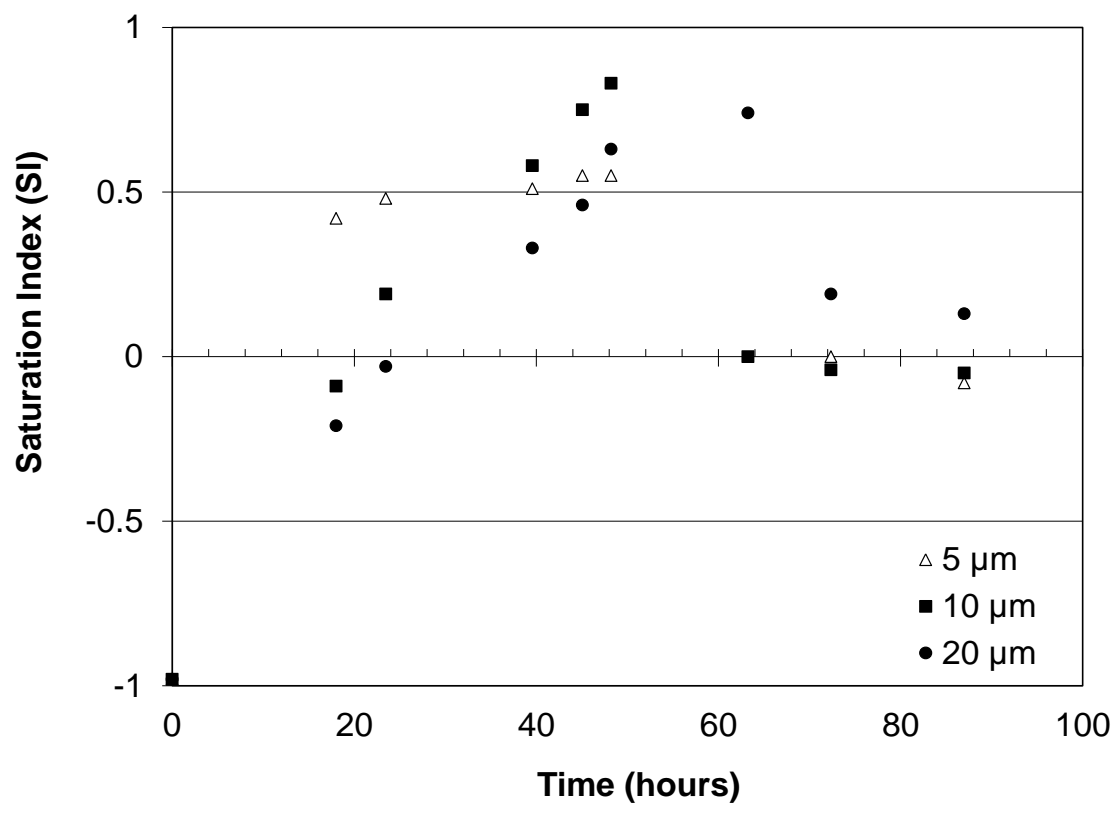

Figure 2. Evolution of the $\mathrm{NaCl}$ saturation index through time due to evaporative water loss, for three different capillary sizes. 
Despite the uncertainty on the basic data (exact value of the meniscus retreat, moles number of precipitated $\mathrm{NaCl}$ ), the behavior followed the expected trend: precipitation happens at low supersaturation, reached at different times depending on the drying kinetics. This first stage was completely "normal" with respect to what happens under drying conditions: the solution concentration increases until nucleation starts. Note that precipitation started after 50 to 60 hours, consistent with the duration of the observed linear retreat of the meniscus (Fig. 1), which is related to a constant rate of evaporation before the precipitation event.

\section{3 $\mathrm{NaCl}$ precipitates: plugging the tube}

The precipitate is always solid and develops at the liquid-air interface (Fig. 3), a finding consistent with the conclusions of previous experiments (e.g. [26-27]).
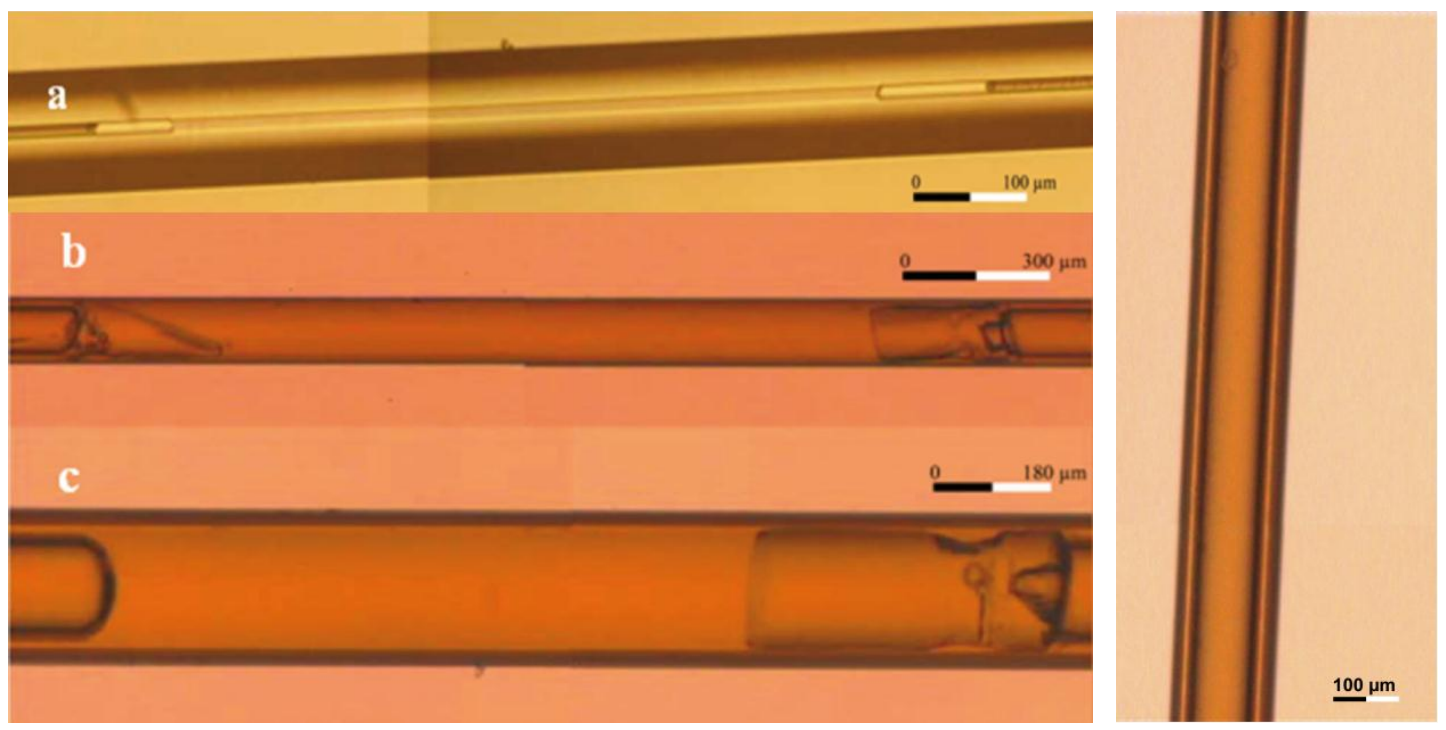

Figure 3. In the upper $\mathrm{a}$ and $\mathrm{b}$ tubes $(\mathrm{a}: \varnothing=10 \mu \mathrm{m} ; \mathrm{b}: \varnothing=100 \mu \mathrm{m}$ ), liquid water is trapped between two solid $\mathrm{NaCl}$ plugs. In the lower c tube (c: $\varnothing=180 \mu \mathrm{m})$, only one side is closed and the solution continues evaporating through the opposite end. To the right, a photograph of an empty tube $(\varnothing=100 \mu \mathrm{m})$.

Halite precipitates are massive in any situation, and display a cubic shape in the Petri dish experiment (Fig. 4), which is the idiomorphic habit at low supersaturation (e.g. [28]). No crystallographic difference was observed between the capillary- and Petri-dish experiments, 
whatever the internal diameters of the tubes. As expected, there was no evidence of any pore-size effect on the salt precipitation process.

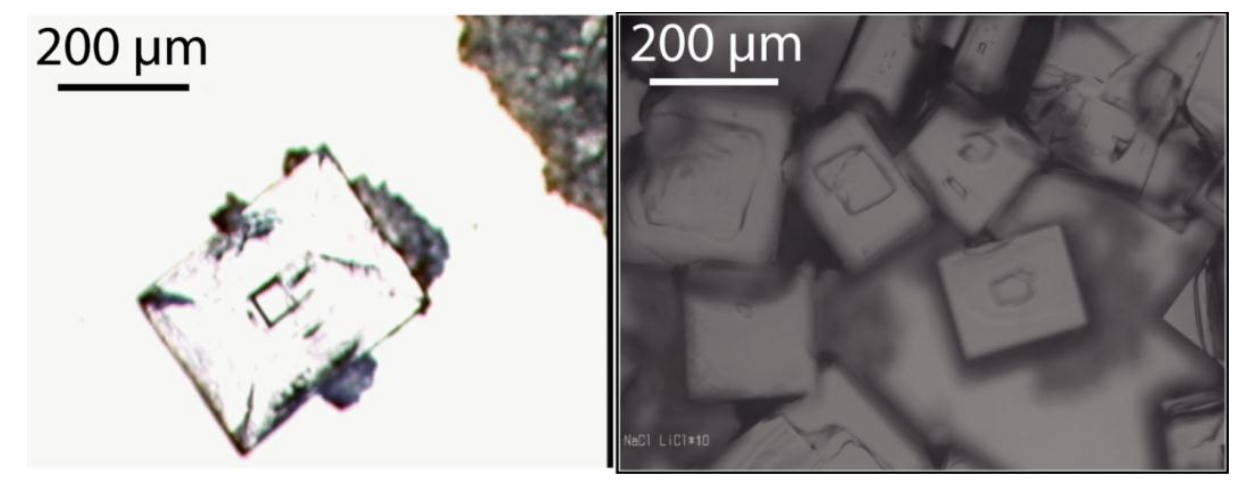

Figure 4. Shape and size of $\mathrm{NaCl}$ crystals growing freely in a Petri dish submitted to $24 \% \mathrm{RH}$ and $20^{\circ} \mathrm{C}$.

In the capillary tubes, we observed (Fig. 3) that precipitation occurs at the liquid-air interfaces, either at both interfaces when the capillary column is at equal distance from the two tube inlets, or at one liquid-air interface when the evaporation is faster on one side of the column. In the latter case, the remaining solution nurtures the initial precipitate until complete disappearance of the aqueous solution. In other words, the capillary column is continuously evaporating through the free interface due to the dry external atmosphere, driving the salt growth that occurs at the pre-existing solid surface (low-cost epitaxial growth). However, when the plugging is bilateral, the system is closed and no significant variation in the water or crystal volumes occurs, except negligible (in terms of mass transfer) changes in the size of the $\mathrm{NaCl}$ plugs. This indicates that the system is no longer evaporating and that the solutioncrystal phase transitions appear to have halted.

The last significant observation is the systematic location of crystal nucleation and growth at the air-water interface. This is commonly observed in such experiments (e.g. [26-27]) and points to the predominant role played by the evaporation front in precipitation: the concentration of the surficial solution is slightly higher than the bulk one as experimentally observed and numerically simulated ([29]). A direct consequence of such crystal growth at the tube inlets is a drastic change in topology of the cylindrical tube: the water-filled volume 
seems isolated from the rest of the system, and appears disconnected from the exterior (see especially Fig. 3a). This experiment shows that the connectivity of any given porous network can change when secondary salt grows through time, depending on the filling solution and local drying conditions. In a real-channel network, such secondary $\mathrm{NaCl}$ precipitation should contribute to increasing the total volume of immobile water. In addition to capillary and adsorbed water, this type of occluded liquid (with a significant volume) is immobilized because it is no longer hydrodynamically connected to flowing water. In this respect, our experimental set-up reproduces the UZ situations, where disseminated capillary water occurs at different matrix potentials, certainly not all connected to percolation channels.

\subsection{The second phase transition: bubble growth}

When the capillary tubes are plugged at both ends (bilateral), the water column is completely isolated from the rest of the system; it might be concluded that the system has reached thermodynamic equilibrium, with no further driving force for a phase transition. Yet, after about three months of regular observations, we observed the appearance of a bubble in the water column (Fig. 5), at varying distance from the $\mathrm{NaCl}$ plugs (Fig. 6). This fact requires that the $\mathrm{NaCl}$ plugs did not completely close the system and left tiny ring spaces between the $\mathrm{NaCl}$ and the tube walls, enabling an interaction between the occluded liquid and the in-tube atmosphere. The persistence of such tiny spaces can be related to the general occurrence of liquid films at grain-grain contacts, ubiquitous in natural environments (e.g. [30-31]).

Once that fact had been established we had to account for the bubbling. At first sight, this could correspond to the receding of the air-liquid interface due to a continuous evaporation process, though slowed down by the reduction of the interface area now formed by an annular space. 


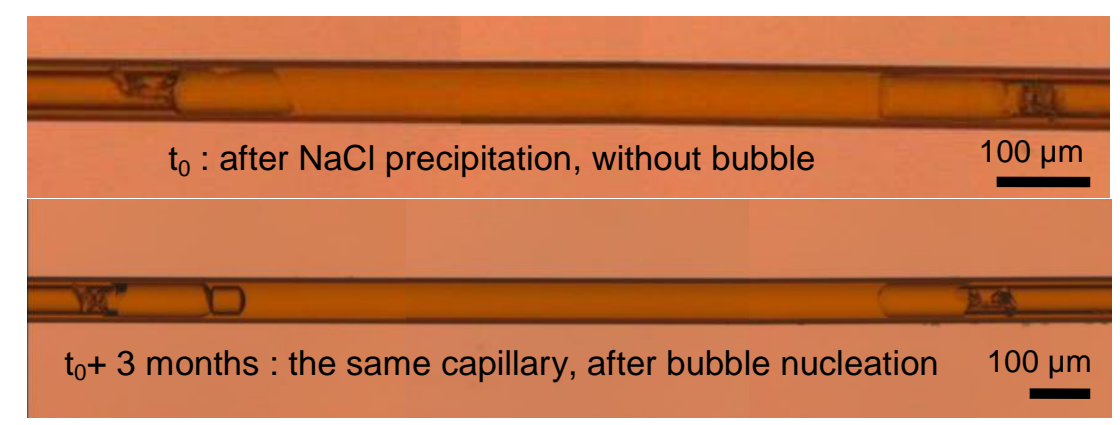

Figure 5. Bubbling after three months in liquid apparently occluded by two $\mathrm{NaCl}$ caps located at the air-water interfaces.

According to this assumption, slow evaporation along the $\mathrm{NaCl}$ plugs may continuously consume water stock along the plugs. After a sufficient time, the liquid-air interface should recede inside the large volume behind the $\mathrm{NaCl}$ plug, resulting in an apparent bubbling in the water column. This scenario can account for the bubbling shown in Figure 6e, and possibly $6 \mathrm{~d}$, where the bubble appears stuck to a $\mathrm{NaCl}$ cap. However, this sketch does not explain why bubbling can appear in the liquid column itself, at some distance from all possible interfaces where vaporization happens (see especially Fig. 6a, f). In these cases, the gas bubble appears to be surrounded by liquid, indicating that the phase transition obeys a driving force belonging to the aqueous solution itself. Even the bubbles growing in the capillary tubes of Figs. $6 b$ and $6 c$ are surrounded by liquid. In such a scenario, the bubbles would continuously grow over time between the plugs, which has not yet been observed.

By eliminating the possibility that the bubbling is connected to mass loss, we had to consider that this phase transition depends only on the liquid properties themselves. And the only way to make boiling a liquid without bringing it to the boiling point is to first superheat it. 


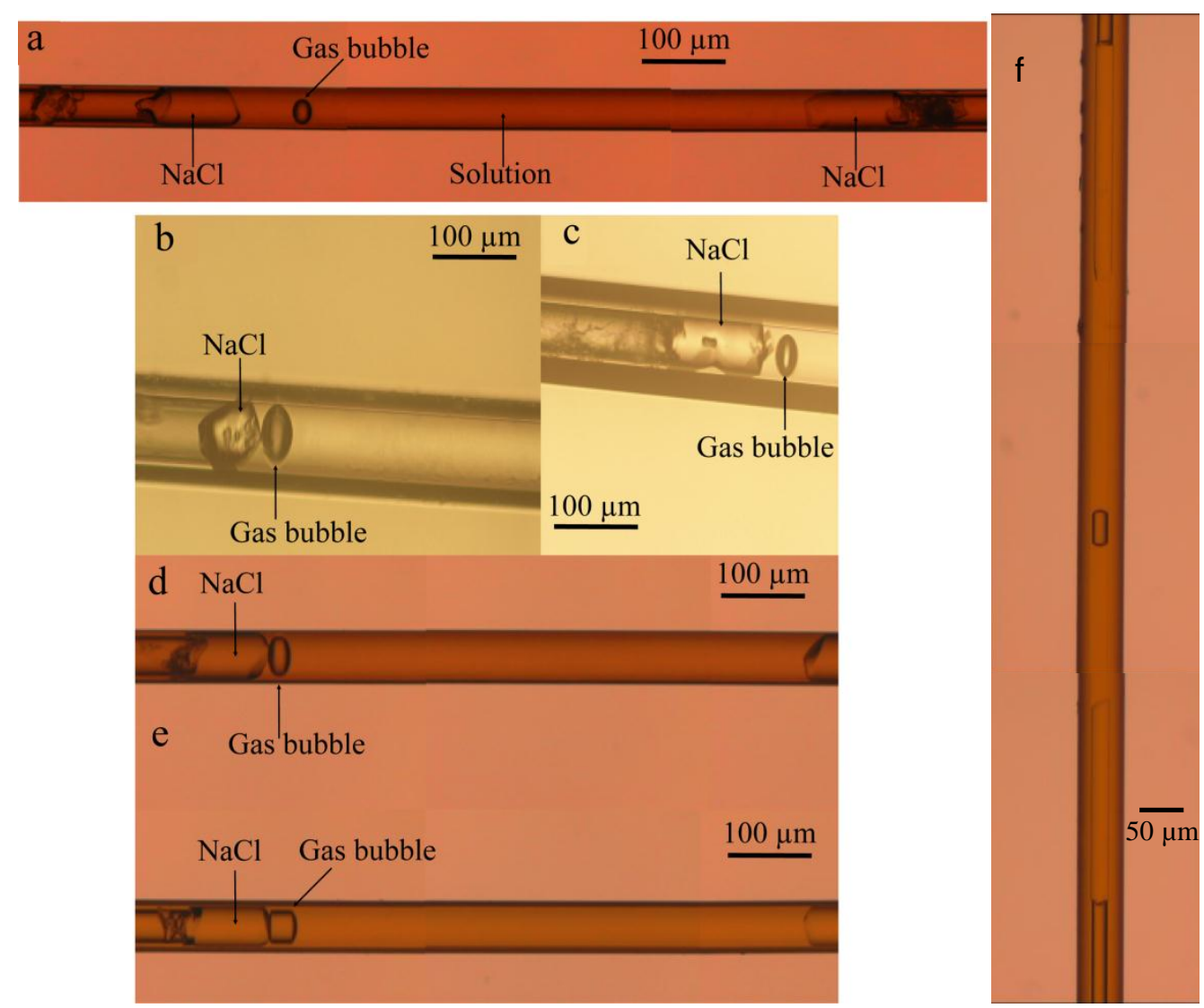

Figure 6. Various locations of bubble nucleation, at varying distances from the two $\mathrm{NaCl}$ plugs, demonstrating that it is a bulk process, and not a liquid-air interface phenomenon.

This second assumption starts again with the existence of tiny ring spaces around the $\mathrm{NaCl}$ plugs. This time, however, the spaces were filled with an aqueous solution that capillarizes to reach equilibrium with the in-tube air $\mathrm{RH}$ (Kelvin law). Additionally, for the capillary liquid to be stable, the geometrical Young-Laplace condition needs to be fulfilled with a sufficiently small space diameter to obey the law (Fig. 7). However, this capillary aqueous solution extends continuously in the capillary tube behind the plugs, where the required geometrical conditions obviously cannot be met (Fig. 7). In fact, we had created an "ink-bottle configuration" as soil scientists call it, a continuous liquid column imbibing a differently sized pore space. From a chemical point of view, the properties of the liquid were now shifted according to the capillary chemical potential. For instance, this liquid has a lower saturation vapor pressure than that predicted by the usual saturation curve (Kelvin law), and so it can nucleate vapor like water heated beyond $100{ }^{\circ} \mathrm{C}$ at atmospheric pressure, which makes this 
into a superheated water. Actually, there is a nucleation barrier — the energy cost to create a liquid-air interface - but, as predicted by the Classical Nucleation Theory (CNT hereafter), it is a matter of time before this barrier is trespassed. For this reason we can call it a metastable superheated liquid. On the whole, a liquid solution disobeying the Young-Laplace law has a limited lifetime depending primarily on the superheating intensity (e.g. [17,32]).

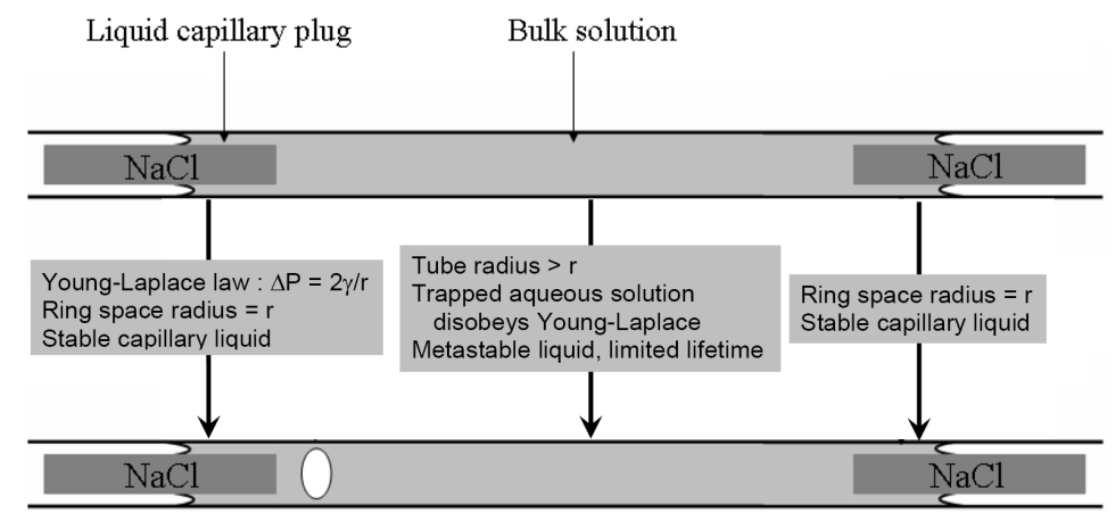

Figure 7. Simplified sketch of the cavitation process, highlighting the continuity between the capillary films around crystal plugs and the superheated liquid volume behind.

As a consequence, we can conclude that the trapped liquid is indeed a metastable superheated liquid prone to bubble nucleation when its characteristic lifetime (here three months) is reached. Thus, the bubble appearance is a cavitation ${ }^{1}$ event, that is to say a vapor explosion (= high nucleation rate, or rapid phase transition) related to an internal disequilibrium inside the mother liquid (e.g. [33]). The rate of nucleation of a critical-sized vapor bubble depends on the distance-to-equilibrium experienced at the time of transition: the more the mother liquid is superheated, the faster will be the liquid-to-vapor nucleation that restores equilibrium, and the more powerful is cavitation.

The complete process is a centripetal $\mathrm{NaCl}$ growth at low supersaturation (massive shape) able to pull a residual liquid film just between the growing solid and the wall tube. When the characteristic distance meets the Young-Laplace condition, depending on the average local $\mathrm{RH} \quad(24 \%<\mathrm{RH}<75 \%$, see above), the liquid along the crystal "capillarizes" and stops

\footnotetext{
${ }^{1}$ Another definition of "cavitation" in liquids relates to a subsequent collapse of the newly-created gas cavities under certain conditions. This implosion releases a very large amount of energy (typically, $1-10^{18} \mathrm{~kW} / \mathrm{m}^{3}$ ) and is used to produce physical and chemical transformations.
} 
evaporating, thus halting the concentration of the solution. As the chemical potential of the capillarized solution has changed, the thermodynamic equilibrium of the solution- $\mathrm{NaCl}$ reaction changes as well (e.g. [2,4,7,8,10,17,19]).

\section{DISCUSSION}

As far as we know, our experiments are the first to record in a direct manner the metastabilization and subsequent cavitation of a liquid. Interestingly, our record is at the channel scale, in a porous ink-bottle configuration that commonly occurs in nature. Many examples are known in the literature (see textbook like [20]) concerning the links between the hysteresis loop (the desorption transition takes place at lower vapor pressure than in the adsorption branch), and the superheating state of the trapped liquid (especially under desorption). This is exactly the so-called ink-bottle effect which is known to affect the dynamic, as well as the static, properties of the soil.

To go beyond the optical evidence, we now had to evaluate the consequences of our findings on the physical chemistry of ink-bottle shaped porous systems. The evidence given above provided firm grounds for stating that capillary traction settles inside the capillary tubes and remains active for about three months. Therefore, this superheated liquid can modify:

- The geomechanical balance at tube scale. As recently demonstrated through experiments ([19]), crystal growth in micrometric pores can, under certain conditions, favor the development of capillary bridges exerting traction on the pore walls. These experiments even showed evidence that this capillary mechanical constraint may microfracture the solid matrix (potentially increasing hydraulic conductivity), while the associated crystal growth contributes to fill the pore spaces (decreasing conductivity).

- The properties of the capillarized liquid, i.e. the local solids are variably weathered by the occluded liquid (e.g. [1-3,7-8,10]) while gas solubility always increases (e.g. [5-6,9,11]). Furthermore, this effect is related to the exact value of capillary pressure. Even the 
weathering kinetics may change with the capillary state whenever the equilibrium constant of the corresponding reaction is significantly modified.

- The pressure-water content and conductivity-water content relationships (the so-called "soil characteristic curves"), or the quantitative correlation between soil structure and its wetting and transport properties. These curves can be decomposed into a capillary term and an adsorbed water term (e.g. [34]), and primarily depend on the three-dimensional topology of the pores. We introduce here the possibility that the porosity may change through time while immobilizing significant volumes of water inside unconnected channels. A quantitative understanding of these soil curves should benefit from a renewed view of the role of the above mechanisms in the three-dimensional networks, depending upon the degree of heterogeneity and the local capillary conditions (dryness, porosity size).

However, this list of possible consequences is interesting only if the capillary pressure and traction generated inside the tubes between the two salt plugs is sufficiently high to promote significant changes in the soil mechanics, hydrodynamics or geochemistry. To verify such qualitative statements, we assessed (see below) the capillary pressure that may exist in our capillary tubes, and the consequent changes in weathering ability of such superheated water on its environment. In particular, we focused on the stability of the $\mathrm{NaCl}$ plugs (would they be re-dissolved or enhanced by this capillarization?), and on the role that cavitation might play on the transport functions.

\subsection{Quantifying the capillary state inside the tube}

According to the Young-Laplace and Kelvin capillarity laws, the capillary parameters (pore radius, water pressure) can be calculated at nil contact angle and with the liquid-air surface tension of the saturated $\mathrm{NaCl}$ solution $\left(\gamma_{\mathrm{NaCl}-\text { air }}=83.5 \mathrm{~mJ} / \mathrm{m}^{2}\right.$ for a plane interface [35]) corrected for capillary curvature with Tolman's formula [36]. However, the size of the capillary films along the $\mathrm{NaCl}$ plugs (i.e. between the plugs and the tube wall) is not known and so the calculation cannot be done this way. In addition, the water pressure decreases to maintain 
the equality of the liquid-vapor chemical potential (Kelvin law, physicochemical condition of equilibrium), meaning that the water pressure could be calculated with the value of the inner air $\mathrm{RH}$. Unfortunately, the experimental conditions inherently cause the system to evolve with a (probably diffusive) vapor profile from interface to tube ends, and so only the range of $\mathrm{RH}$ is known. Indeed, the mean air $\mathrm{RH}$ within the tube is necessarily greater than the external air value $(24 \%)$ and lower than the saturation value (75\%). The corresponding water pressure and Young-Laplace pore radius thus vary between $P_{\text {WATER }}=-1480 \times 10^{5} \mathrm{~Pa}$ and $r_{\text {PORE }}=0.8 \mathrm{~nm}$ for an interfacial air $\mathrm{RH}$ of $24 \%$, to $\mathrm{P}_{\text {WATER }}=10^{5} \mathrm{~Pa}$ and $\mathrm{r}_{\mathrm{PORE}}=\infty$ for an interfacial air $\mathrm{RH}$ of $75 \%$. However, we have to outline that the capillary parameters required for a direct application of the capillarity laws cannot be directly measured.

A first rough estimate can be performed by assuming a constant compressibility of trapped liquid, which allows us to write:

$$
\beta=-\frac{1}{V_{\text {total }}}\left(\frac{\Delta V}{\Delta P}\right)_{T}
$$

Where $\beta$ is the isothermal compressibility (assumed constant, equal to its $20^{\circ} \mathrm{C}, 1$ bar value: $\beta=4.61 \mathrm{~Pa}^{-1}$ ), $V_{\text {total }}$ is the volume (in $\mathrm{m}^{3}$ ) of the liquid column before cavitation, the $\Delta V$ is the volume (inm ${ }^{3}$ ) of the gas bubble after cavitation, so that the $\Delta P$ (in $\mathrm{Pa}$ ) is the negative pressure needed to stretch the liquid to fill the pre-cavitation volume. This simple calculation can be made on our tubes series (Fig. 6), but requires to be aware that the measurements of the lengths of the liquid columns are variably uncertain, due to the small optical field of our set-up (previously evoked). Choosing the two tubes less affected by this uncertainty, we get $680 \times 10^{5} \mathrm{~Pa}$ with the tube figured in $6 \mathrm{a}$, and $-790 \times 10^{5} \mathrm{~Pa}$ with the $6 \mathrm{~d}$ tube. These values plot inside the expected range, and are reasonably consistent, but the associated uncertainty remains large and is rather unknown actually.

For a second, and completely different, estimate of the inner capillary pressure, we propose using the lifetime of the trapped liquid, which was experimentally demonstrated ([32]) to be consistently related to the value of the liquid pressure. El Mekki et al. [32] measured the lifetime of superheated water as a function of liquid pressure, using the micro-thermometry 
technique on synthetic fluid inclusions (e.g. [37]). A data series recorded on pure water trapped in a $50 \times 20 \mu \mathrm{m}$ inclusion in quartz [32] is plotted on Figure 8. We decided to fit these published data, acquired at high liquid tractions along short lifetimes, with the help of the CNT expressions [38] adapted to a heterogeneous nucleation process, which is the most probable nucleation process in real materials. Once fitted, the relationship was extrapolated to determine the possible pressure of a superheated aqueous solution lasting three months.

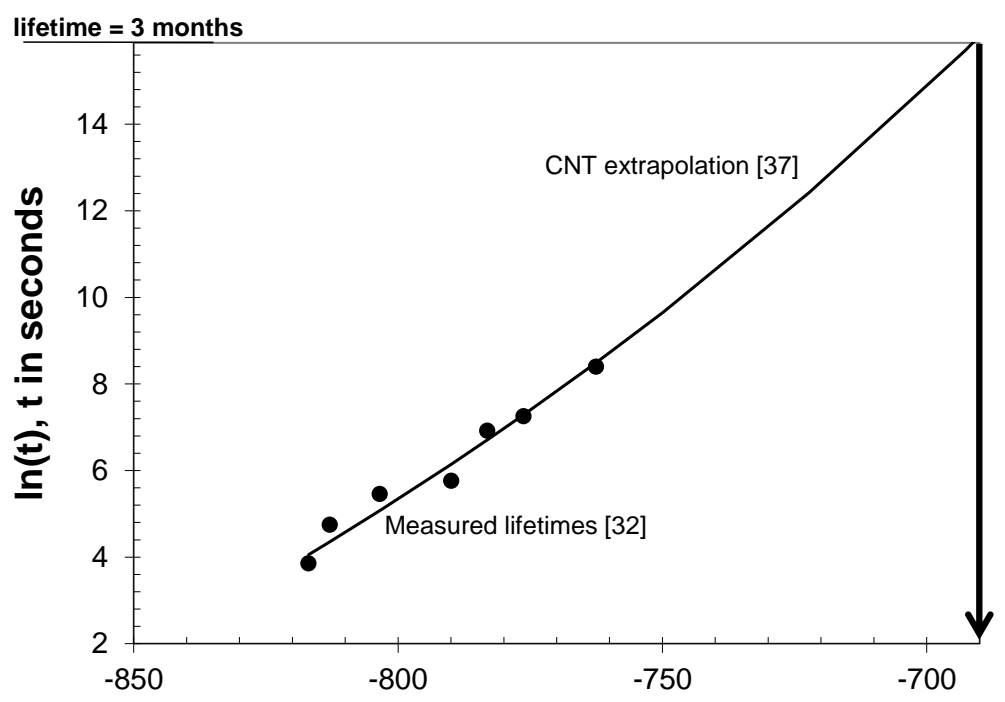

Pressure of the superheated liquid $\left(\times 10^{5} \mathrm{~Pa}\right)$

Figure 8. Estimate of the pressure before cavitation using the lifetime of the capillary liquid (3 months) compared to a lifetime deduced by extrapolating the measurements from [32] according to the Classic Nucleation Theory (see text).

To model these data, we calculated the theoretical (according to CNT) mean lifetime of a liquid superheated at a given pressure, taken as the reciprocal of the nucleation rate at constant volume (e.g. [39]):

$$
\langle\tau\rangle=1 / J
$$

where $\tau$ is the lifetime and $\mathrm{J}$ the nucleation rate.

The nucleation rate was calculated considering a heterogeneous nucleation on a smooth rigid surface (equation 44 in [38]): 


$$
J=N^{2 / 3} S\left[\frac{2 \gamma_{\text {water-air }}}{\pi m B F}\right]^{1 / 2} \exp \left(\frac{-16 \gamma_{\text {water-air }}{ }^{3} F}{3 k T\left(P_{\text {air }}-P_{\text {water }}\right)^{2}}\right)
$$

where $N$, with its exponent, expresses the number density of the liquid molecules at the liquid-solid contact (molecules $/ \mathrm{m}^{2}$ of interface), assuming a molecular surface for $\mathrm{H}_{2} \mathrm{O}$ amounting to $15 \AA^{2} /$ molecule (e.g., [40]); $\gamma_{\text {WATER-AIR }}$ is the water-air surface tension $\left(\mathrm{N} . \mathrm{m}^{-1}\right)$; and $m$ is the mass of one water molecule $(\mathrm{kg} /$ molecule). $\mathrm{B}, \mathrm{F}$, and $\mathrm{S}$ are calculated according to: $B \approx 1-1 /\left[3 .\left(1-P_{\text {WATER }} / P_{\text {AIR }}\right)\right]$, amounting to $2 / 3$ when $\mathrm{P}_{\text {WATER }}$ is smaller than $\mathrm{P}_{\text {AIR }}$ (the common case in cavitation); $F \equiv\left(2-3 \mu+\mu^{3}\right) / 4$; and $S \equiv(1-\mu) / 2$, where $\mu=-\cos \theta$, with $\theta$ the contact angle of the growing bubble with the nucleating surface.

Using a contact angle of $96^{\circ}$, a high value characterizing a hydrophobic surface (a correct assumption with a high-temperature pure quartz), the measurements perfectly fit with no more adjustment (Fig. 8). Extrapolating the fitted curve up to a lifetime of three months gives us a $-690 \times 10^{5} \mathrm{~Pa}$ liquid pressure, roughly half the maximum possible value in the capillaries $\left(-1480 \times 10^{5} \mathrm{~Pa}\right.$, see above). This would correspond to a pore radius of the capillary films around the $\mathrm{NaCl}$ plug of about $2 \mathrm{~nm}$, obviously invisible with an optical microscope.

Our water pressure calculation is only a rough estimate of the actual value, since many characteristics differ between the $\mathrm{NaCl}$ solution trapped in fused-silica capillaries (this experiment) and the reference water fluid inclusions in pure quartz [32]. However, the calculated value is quite consistent with the experimental conditions and falls within the expected range. This illustrates that the superheating intensity could reach very high levels, acting on quite large liquid volumes, justifying its inclusion in the geochemical reasoning.

\subsection{Capillary "weathering" geochemistry}

According to thermodynamics, the chemical reaction between the $\mathrm{NaCl}$ cap and the surrounding aqueous solution evolves in order to minimize the chemical potential of the system. Therefore, a modification of the chemical potential due to capillarization inside the solution necessarily modifies the equilibrium constant of the corresponding reaction. In the 
vocabulary of capillary geochemistry, this corresponds to anisobaric equilibrium, since only the solution undergoes the capillary state, which is written as:

$$
d \Delta_{R} G_{c a p}=\int_{P_{r f}=0.1}^{P}\left(V_{N a^{+}}+V_{C l^{-}}\right) d P=R T \ln \frac{K^{\circ}}{K_{\text {anisobaric }}}
$$

where $R$ is the ideal gas constant (in $\mathrm{J}_{\mathrm{mol}}{ }^{-1} \cdot \mathrm{K}^{-1}$ ); $T$ the temperature (in $\mathrm{K}$ ); $d \Delta_{R} G_{\text {cap }}$ (in $\mathrm{J}_{\mathrm{mol}}{ }^{-1}$ ) the change of the Gibbs free energy due to capillarization inside the system; $V_{i}$ (in $\mathrm{m}^{3} \cdot \mathrm{mol}^{-1}$ ) the molar volume of the $\mathrm{i}^{\text {th }}$ aqueous species; $P$ (in $\mathrm{Pa}$ ) the liquid phase pressure; and $K_{\text {anisobaric }}$ (also noted $K_{P}$ in the graph) and $K^{\circ}$ the equilibrium constants of the halite dissolution reaction at $P$ and $10^{5} \mathrm{~Pa}$, respectively. This configuration is called anisobaric $[2,7,8,10]\left(K_{\text {anisobaric }}\right)$, since the cubic solid and the capillary solution do not experience the same pressure.

The corresponding phase diagram is drawn on Figure 9 using the THERMO-ZNS computer code, built for thermodynamic calculations in capillary contexts (e.g. [10]). It shows that the corresponding $K_{\text {anisobaric }}$ increases with decreasing $P$, i.e. the halite is more soluble in capillary solution than in a free solution. In other words, a bulk solution at equilibrium with halite tends to become dissolving when it is capillarized.

Such calculations with the equilibrium constants relate to the standard thermodynamic properties of the chemical compounds of interest, and show how the activities of the dissolved species evolve with capillary pressure (Fig. 9, left y-axis). The conversion from activity to concentrations of the dissolved species normally requires calculation of the activity coefficients with a suitable model. However, at saturation with respect to halite (or close to), the $\mathrm{Na}^{+}$and $\mathrm{Cl}^{-}$activity coefficients are known to be close to 1 . This renders the conversion to aqueous concentrations straightforward and enables organizing the data along the right yaxis on Fig. 9. This, in turn, directly gives the concentration of ionic species in an aqueous solution (under variably capillary state) at equilibrium with halite. 


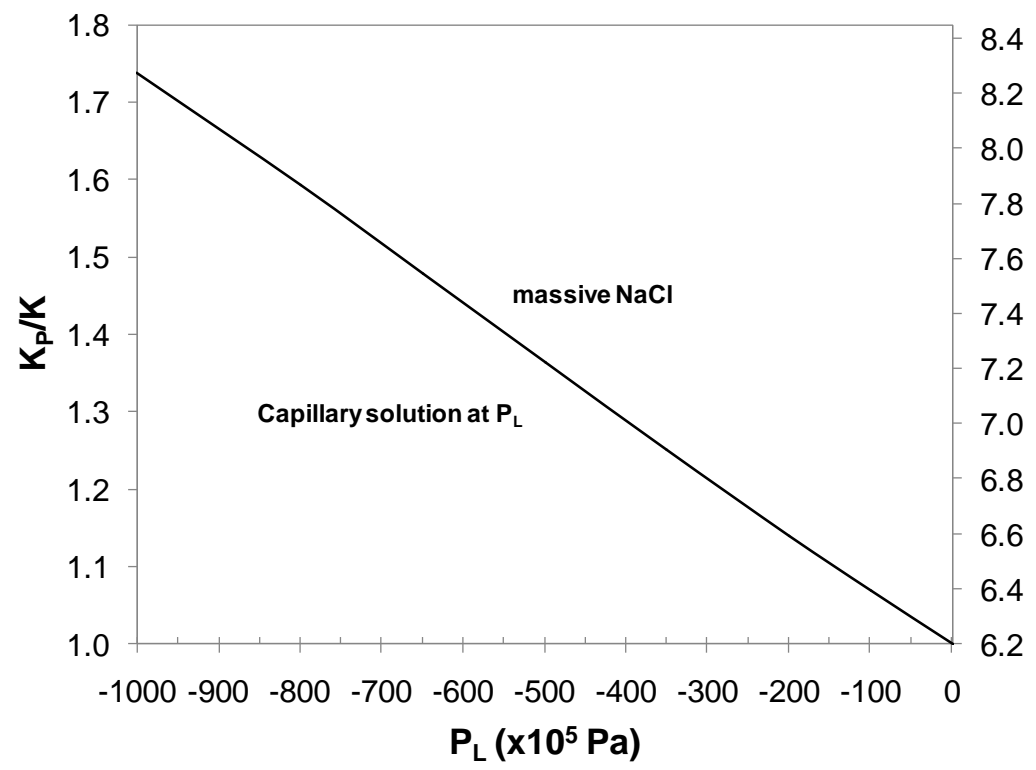

Figure $9 . \mathrm{K}_{\mathrm{p}} / \mathrm{K}^{\circ}$ ratio and $\mathrm{NaCl}$ molality at equilibrium (see text) for the $\mathrm{NaCl}$ reaction with a solution under variable capillary state (thermodynamic properties from the Thermoddem database, available at http://thermoddem.brgm.fr/).

Capillarization of the solution thus appears to be a weathering agent as long as the liquid pressure is modified. Figure 9 shows that the geochemical effect requires a relatively high capillary tension to become significant in terms of mass balance. Pettenati et al. [17] evaluated at $-200 \times 10^{5} \mathrm{~Pa}$ the pressure threshold to obtain a geochemical effect. But the potential impact of such capillary weathering is also related to the area of the solid-liquid interaction, and to the associated liquid volume that can be transferred at the profile scale with its "capillarized salinity". The tube wall is entirely in contact with a $5-10 \mathrm{~cm}$ long liquid column that all around interacts with its capillary properties. A second point worth to be noted is that the solutes mass can be transferred outside the channel, once cavitation has freed the liquid volume from the retention by capillary forces.

\subsection{Cavitation and transport function in UZ}

The potential role of cavitation on the desaturation and drying of porous materials/media was earlier described [14-16]. Actually, as soon as cavitation occurs, the liquid column becomes 
normal free water, unable to resist gravity. In real situations, the liquid occluded and held immobile in the pores by capillary forces, can, after cavitation, flow downward and exit the channel through the tiny spaces along the $\mathrm{NaCl}$ plugs. Or and Tuller [16] outlined that this is a potential mechanism for liquid drainage in wet porous media, enabling liquid displacement even in the absence of a continuous gaseous phase. Additionally, McManus and Davis [15] stressed that such drainage implies strong changes in soil strength.

This non piston-flow drainage related to liquid cavitation can occur at any water pressure. Actually, depending on local conditions, the probability of water cavitation depends first on thermal fluctuations (homogeneous nucleation), but also on many others factors generally enhancing nucleation probability (impurities, surface states, etc): this is the heterogeneous nucleation (real) world. Shmulovich et al. [37] illustrated how extreme tensile strength (cavitation as a spontaneous nucleation process) is a varying limit, even in the same sample from one fluid inclusion to another. In other words, each situation (a water volume in a given material under certain environmental conditions) has its own extreme tensile strength with a nil lifetime. When the studied water volume is differently superheated (due to variation in the local environment), its lifetime varies between zero at extreme tension and infinite when the internal water pressure is again at saturation value. Between the two, the lifetime of a more or less superheated liquid can vary from some seconds to, potentially, millions of years.

In the real world, superheating is affected by the range of variation in air humidity (Kelvin law), which leads to changing the chemical potential of the contacting liquid, as well as by the topology of the local space network obeying or not the Young-Laplace relationship, not to speak of the numerous factors decreasing the nucleation barrier. The simplicity of these two laws coupled to the immense diversity of the local situations make the resulting scenarios almost infinite.

Moreover, cavitation has been correctly called a large-scale drainage process [16]. In fact, the cavitation process is associated with acoustic emissions ranging from audible to ultrasonic frequencies, which make the process recordable in a non-invasive way (e.g. [41]). These acoustic emissions are induced by the shock waves resulting from sudden tension 
release in the channel as the stretched liquid is replaced by a biphasic vapor-liquid assemblage at saturation pressure (e.g. [42]). The shock waves and subsequent sound waves travelling inside the host media contribute to drastically decreasing the nucleation energy barrier, which may provoke the cavitation of any metastable volume trapped at some distance from the one that cavitated first. Cavitation in a given capillary volume can thus provoke the boiling of any (not too distant) superheated volume through a sort of chain reaction.

Another aspect is the geochemical aspect of the superheating. The volume trapped between the two $\mathrm{NaCl}$ plugs is quite significant and has two interesting features: 1) It is immobile as long as it does not cavitate and thus can interact with local solids; 2) It has the specific properties of a superheated liquid with its own equilibrium constants of reaction (e.g. [1,2,4,710]; also, see the previous section). Once the cavitation occurs, the liquid column turns to be mobile, and moves with its chemical signature gained during its metastable period.

\section{CONCLUSIONS AND PERSPECTIVES}

We present simple and direct experiments illustrating the ability of superheating of a liquid volume trapped in cylindrical micrometric capillary tubes. The key feature is the possibility for (Young-Laplace) capillary bridges to occur somewhere in the host capillary system under drying conditions. The precipitation of solids from a concentrated filling solution results in the almost complete plugging of the capillary space. Only a tiny (invisible under optical microscopy) annular space must remain open between the capillary tube and the grown solid plug, enabling capillary bridging. The existence of capillary films around the $\mathrm{NaCl}$ plugs is deduced from evidence that the trapped liquid is superheated, which is only possible through applying the Kelvin law (lower vapor pressure at a liquid-air interface than the saturation vapor pressure). This requires an ink-bottle configuration, which is exactly that allowed by a micrometric capillary tube plugged by $\mathrm{NaCl}$ plugs just nanometrically narrower than the host tube. The resulting situation is familiar to natural scientists: this is the same arrangement as 
that experienced by tree sap in $10-400 \mu \mathrm{m}$ xylems loaded by regularly located $5-300 \mathrm{~nm}$ vessel-to-vessel pit membranes (e.g. $[8,43])$.

Hydraulically, the $\mathrm{NaCl}$ plugs deeply modify liquid mobility as a whole, by isolating part of the total volume. This should contribute to increasing the complexity of the hysteresis relationship between drainage and wetting regimes in a porous media, as earlier concluded [16]. Cavitation of superheated water was earlier studied by tree physiologists, because it causes embolism of the xylems and thus constitutes a serious vital problem (e.g. [44]). The problem is less crucial for a soil network, but shows that cavitation can play an important role with respect to the water budget.

The real novelty of our results, however, concerns the geochemical aspects of the question. First, we noted the ability of any drying process to dramatically increase the heterogeneity of an initially simple system, as salt precipitation changes the inner topology of the pore space. Second, we again demonstrated the ability of narrow spaces for capillarity to take place; Bouzid et al. [19] found this process in pore membranes of micrometric thickness, but here we show its existence in decimeter-long open capillaries. Despite the fact that air humidity in the tube is necessarily higher than the external $\mathrm{RH}$, capillarization occurs and appears able to expose the system to significant levels of superheating.

An important fact is the potentially large amount of liquid that may be capillarized in the UZ. According to the Young-Laplace law, high capillary traction seems to apply to only very tiny volumes of liquid. The ink-bottle effect, however, enables sustaining very large volumes of stretched water because of the narrow liquid-air interfaces where the supporting capillary bridges occur. This result opens new perspectives in the UZ geochemistry field, since it paves the way for renewing the writing of the equilibrium constants of geochemical reactions. Generally speaking, when capillary solutions interact with pre-existing solids, they are better solvents than the bulk solutions, a conclusion that was earlier inferred from phase transitions in pores [19], or from industrial chemistry processes (e.g. [22-23]). This directly affects mass balance in the UZ, which should now be re-discussed through integrating the superheating domain of thermodynamic properties of the resident solutions. 
Acknowledgements - Two anonymous reviewers are greatly acknowledged for their fair judgments which helped in restructuring a first version of the manuscript. Dr A. Imre, KFKI (Budapest, Hungary), and visiting professor at the ISTO laboratory, is greatly acknowledged for providing the idea connected to the equation 2.

\section{REFERENCES}

[1] Mercury L. and Tardy Y. (1997a) C. R. Acad. Sci. Paris 324, 11, 863-873.

[2] Mercury L. and Tardy Y. (1997b) C. R. Acad. Sci. Paris 325, 12, 947-954.

[3] Zilberbrand M. (1997) J. Colloid Interf. Sci. 192, 471-474.

[4] Zilberbrand M. (1999) Aquatic Geochem. 5, 195-206.

[5] Clennell M.B., Hovland M., Booth J.S., and Henry P., and Winters W.J.J. Geophys. (1999) Res. B, 104, 22985-23003.

[6] Henry P., Thomas M., and Clennell M.B.J. (1999) Geophys. Res. B, 104, 23005-23022.

[7] Mercury L. and Tardy Y. (2001) Geochim.Cosmochim. Acta 65, 3391-3408.

[8] Mercury L., Azaroual M., Zeyen H., and Tardy Y. (2003) Geochim. Cosmochim. Acta 67, $1769-1785$.

[9] Mercury L., Pinti D. L., and Zeyen H. (2004) Earth Planet. Sci. Lett. 223, 147-161.

[10] Lassin A., Azaroual M., and Mercury L. (2005) Geochim.Cosmochim. Acta 69, 51875201.

[11] Mercury L. (2006) In "Encyclopedia of Surface and Colloid Science". Ed. P. Somasundara. 2nd Edition; Taylor \& Francis, New York. Vol. 4, pp. 2665-2677.

[12] Rowlinson J.S. and Widom B. (2002) Molecular Theory of Capillarity. Dover Pub., NY, $327 \mathrm{p}$.

[13] Debenedetti P.G. (1996) Metastable Liquids. Concepts and Principles. Princeton Univ. Press, Princeton, New Jersey, 411 p.

[14] Scherer G.W. and Smith D.M. (1995) J. Non-Cryst. Solids 189, 197-211.

[15] McManus K.J. and Davis R.O. (1997) Géotechnique 47, 173-177. 
[16] Or D. and Tuller M. (2002) Water Resour. Res. 38(5), 1061, doi:

10.1029/2001WR000282.

[17] Pettenati M., Mercury L., and Azaroual M. (2008) Applied Geochem. 23, 3799-3818.

[18] Gawin D. and Sanavia L. (2010) Transp. Porous Media 81, 141-160.

[19] Bouzid M., Mercury L., Lassin A., Matray J.M. and Azaroual M. (2011) J. Colloid Interf. Sci. 355, 498-506.

[20] Hillel D. (1998) Environmental Soil Physics. Academic Press, New York. 771 p.

[21] Tindall T.A. and Kunkel J.R. (1999) Unsaturated Zone Hydrology for Scientists and Engineers. Prentice Hall, New Jersey, 624 p.

[22] Chienthavorn O. and Su-in P. (2006) Anal. Bioanal. Chem. 385, 83-89.

[23] Smith R.M. (2006) Anal. Bioanal. Chem. 385, 419-421.

[24] Chauvet F. (2009) Effect of films flow on the evaporation regime of square capillary tubes (in french). Ph.D. thesis, University of Toulouse, 138 p. (available at http://ethesis.inptoulouse.fr/archive/00001047/01/chauvet.pdf).

[25] Lide D.R. (Ed.) Handbook of Chemistry and Physics. $87^{\text {th }}$ edition, CRC Press, Taylor \& Francis, pp. 6-194.

[26] Rodriguez-Navarro C. and Doehne E. (1999) Earth Surf. Process. Landforms 24, 191209.

[27] Benavente D., Garcia del Cura M.A, Garcia-Guinea J., Sanchez-Moral S. and Ordonez S. (2004) J. Cryst. Growth 260, 532-544.

[28] Sunagawa I. (1981) Bull. Mineral. 104, 81-87.

[29] Jungwirth P. and Tobias D.J. (2006) Chem. Reviews 106, 1259-1281.

[30] Renard, F. and P. Ortoleva (1997) Geochim. Cosmochim. Acta 61, 1963-1970.

[31] Anzalone A., Boles J., Greene G., Young K., Israelachvili J., and Alcantar N. (2006) Chem. Geol. 230, 220-231.

[32] El Mekki M., Ramboz C., Perdereau L., Shmulovich K.I., and Mercury L. (2009) In "Metastable systems under pressure". NATO Science for Peace and Security Series A, 
Chemistry and Biology. Edited by S.J. Rzoska, A. Drozd-Rzoska et V. Mazur. Springer Verlag, pp. 279-292.

[33] Reid R.C. (1983) Adv. Chem. Eng. 12, 105-208.

[34] Or D. and Tuller M. (1999) Water Resour. Res. 35, 3591-3605

[35] Leroy P., Lassin A., and Azaroual M. (2010) Geochim. Cosmochim. Acta 74, 5427-5442

[36] Mercury L. and Tardy Y. (2004) Geochim. Cosmochim. Acta 68, 2775-2780.

[37] Shmulovich, K., Mercury L., Thiéry R., Ramboz C., and El Mekki M. (2009) Geochim. Cosmochim. Acta, 73, 2457-2470.

[38] Blander M. and Katz J.L. (1975) AIChE J. 21, 833-848.

[39] Skripov V.P. (1992) J. Non-Equillib. Thermodyn. 17, 193-236.

[40] Puibasset J. and Pellenq R. J.-M. (2004) J. Phys.: Condens. Matter 16 (2004) S5329S5343.

[41] Rosner S., Klein A., Wimmer R., and Karlsson B. (2006) New Phytol. 171, 105-116.

[42] Tyree M.T. and Sperry J.S. (1989) Annual Rev. Plant Phys. Plant Mol. Biol. 40, 19-38.

[43] Tyree M.T. and Zimmermann M.H. (2002) Xylem Structure and the Ascent of Sap.

Springer Series in Wood Science (T.E Tindell Ed.), Springer Verlag, $2^{\text {nd }}$ edition, $283 \mathrm{p}$.

[44] Cochard H. (2006) C.R. Physique 7, 1018-1026. 